\title{
Diverse Arctic lake sediment microbiota shape methane emission temperature sensitivity
}

Joanne B. Emerson ${ }^{1+}$, Ruth K. Varner ${ }^{2,3^{*}}$, Martin Wik ${ }^{4}$, Donovan H. Parks ${ }^{5}$, Rebecca B. Neumann ${ }^{6}$, Joel E. Johnson ${ }^{2}$, Caitlin M. Singleton ${ }^{5,++}$, Ben J. Woodcroft ${ }^{5}$, Rodney Tollerson $\mathrm{II}^{1}$, Akosua Owusu-Dommey ${ }^{7+++}$, Morgan Binder $^{7++++}$, Nancy L. Freitas ${ }^{7,++++}$, Patrick M. Crill ${ }^{4}$, Scott R. Saleska ${ }^{8}$, Gene W. Tyson ${ }^{5}$, and Virginia I. Rich ${ }^{1^{*}}$

${ }^{1}$ Department of Microbiology, The Ohio State University, $496 \mathrm{~W} 12^{\text {th }}$ Ave, Columbus, OH 43210 , USA.

${ }^{2}$ Department of Earth Sciences, University of New Hampshire, 56 College Road, Durham, NH 03824, USA

${ }^{3}$ Earth Systems Research Center, Institute for the Study of Earth, Oceans and Space, University of New Hampshire, 8 College Road, Durham, NH 03824, USA

${ }_{4}$ Department of Geological Sciences, Stockholm University, Stockholm 106 91, Sweden

${ }^{5}$ Australian Centre for Ecogenomics, School of Chemistry and Molecular Biosciences, University of Queensland, Brisbane 4072, Australia

${ }^{6}$ Civil \& Environmental Engineering, University of Washington, 201 More Hall, Box 352700, Seattle, WA 98195-2700

${ }^{7}$ Department of Environmental Science, University of Arizona, AZ 85721, USA

${ }^{8}$ Department of Ecology and Evolutionary Biology, University of Arizona, Tucson, AZ 85721, USA

${ }^{+}$Current address: Department of Plant Pathology, University of California, Davis, One Shields Ave, Davis, CA 95616 USA

${ }^{++}$Current address: Center for Microbial Communities, Department of Chemistry and Bioscience, Aalborg University, Aalborg 9220, Denmark

${ }^{+++}$Current address: Parkland Hospital, 5200 Harry Hines Blvd., Dallas, TX 75235

${ }^{++++}$Current address: John C. Lincoln Health Network, 34975 N North Valley Pkwy Ste 100, Phoenix, AZ 85086

${ }^{+++++}$Current address: Energy and Resources Group, University of California, Berkeley

*Correspondence to: ruth.varner@unh.edu, rich.270@osu.edu

\section{Abstract}

Northern post-glacial lakes are a significant and increasing source of atmospheric carbon (C), largely through ebullition (bubbling) of microbiallyproduced methane $\left(\mathrm{CH}_{4}\right)$ from the sediments ${ }^{1}$. Ebullitive $\mathrm{CH}_{4}$ flux correlates strongly with temperature, suggesting that solar radiation is the primary driver of these $\mathrm{CH}_{4}$ emissions ${ }^{2}$. However, here we show that the slope of the temperature$\mathrm{CH}_{4}$ flux relationship differs spatially, both within and among lakes.

Hypothesizing that differences in microbiota could explain this heterogeneity, we 
45 compared site-specific $\mathrm{CH}_{4}$ emissions with underlying sediment microbial

46 (metagenomic and amplicon), isotopic, and geochemical data across two post-

47 glacial lakes in Northern Sweden. The temperature-associated increase in $\mathrm{CH}_{4}$

48 emissions was greater in lake middles-where methanogens were more

49 abundant—-than edges, and sediment microbial communities were distinct

50 between lake edges and middles. Although $\mathrm{CH}_{4}$ emissions projections are

51 typically driven by abiotic factors ${ }^{1}$, regression modeling revealed that microbial

52 abundances, including those of $\mathrm{CH}_{4}$-cycling microorganisms and syntrophs that

53 generate $\mathrm{H}_{2}$ for methanogenesis, can be useful predictors of porewater $\mathrm{CH}_{4}$

54 concentrations. Our results suggest that deeper lake regions, which currently

55 emit less $\mathrm{CH}_{4}$ than shallower edges, could add substantially to overall $\mathrm{CH}_{4}$

56 emissions in a warmer Arctic with longer ice-free seasons and that future $\mathrm{CH}_{4}$

57 emission predictions from northern lakes may be improved by accounting for

58 spatial variations in sediment microbiota.

\section{Main text}

61 At high latitudes, lakes and ponds are recognized as a large and

62 understudied source of methane $\left(\mathrm{CH}_{4}\right)^{1,3,4}$, a radiatively important trace gas.

63 Post-glacial lakes (formed by glaciers and receding ice sheets, leaving mineral-

64 rich sediments) represent the largest lake area at high latitudes ${ }^{5}$. Because of

65 their areal extent, these lakes contribute to approximately two-thirds of the

66 model-predicted natural $\mathrm{CH}_{4}$ emissions above $50^{\circ} \mathrm{N}$ latitude ${ }^{1}$. Their

67 geochemistry and emissions are distinct from thermokarst lakes formed by

68 permafrost thaw ${ }^{6}$. With warming, permafrost thaw, and predicted increased 
69 precipitation, northern lakes are expected to receive more terrestrially-derived

70 carbon, likely increasing their carbon dioxide $\left(\mathrm{CO}_{2}\right)$ and $\mathrm{CH}_{4}$ emissions ${ }^{7,8}$.

71 Ebullition commonly accounts for $>50 \%$, sometimes $>90 \%$ of the $\mathrm{CH}_{4}$ flux

72 from post-glacial lakes, with the remainder primarily attributed to diffusion-limited

73 hydrodynamic flux ${ }^{9,10}$. Ebullition moves $\mathrm{CH}_{4}$ rapidly from sediments directly to the

74 atmosphere, typically bypassing microbial $\mathrm{CH}_{4}$ oxidation in the water column ${ }^{11}$.

75 Incoming short-wave radiation and sediment temperature have been identified as

76 strong predictors of ebullitive $\mathrm{CH}_{4}$ emission from sub-arctic post-glacial lakes on

77 an annual basis, with higher temperature increasing emissions during the ice-free

78 season $^{2,12}$. However, the extent and drivers of spatial variability in this

79 temperature response, particularly within lakes, are poorly understood.

80 To address this knowledge gap, we analyzed $\mathrm{CH}_{4}$ emissions over a six-

81 year period and collected underlying sediment cores in July 2012 from the littoral

82 ("edge") and pelagic ("middle") locations of two shallow post-glacial lakes,

83 Mellersta Harrsjön and Inre Harrsjön, (Figure S1, Supplementary Table 1). These

84 lakes are part of the Stordalen Mire complex, a hydrologically interconnected,

85 discontinuous permafrost ecosystem encompassing post-glacial lakes and a

86 mosaic palsa/wetland in approximately equal portions ${ }^{13}$. The lakes contribute

$87 \sim 55 \%$ of the total ecosystem $\mathrm{CH}_{4}$ loss $^{2}$ and are model sites for studying ebullitive

88 emissions, which were collected at lake surfaces for the six summers from 2009-

$892014^{12,14}$ every 1-3 days ${ }^{9}$. Here, we linked site-specific (lake edge vs. middle)

$90 \mathrm{CH}_{4}$ emissions to analyses of the microbiota and biogeochemistry in the

91 underlying sediments. 
$92 \quad$ Previous work has shown that annual ebullitive emissions are consistently

93 higher from these lakes' shallow littoral zones than their deeper pelagic zones ${ }^{9,15}$,

94 as expected, since the shallow sediments experience higher temperatures for

95 longer periods and also receive more substrate input from aquatic vegetation ${ }^{16}$.

96 However, assessing the temperature sensitivity of ebullition for the two lake

97 zones in this study revealed a previously unnoticed significant difference, with

$98 \sim 5$-fold higher temperature sensitivity in lake middles relative to edges (Figure 1,

99 Supplementary Table 2). Predicted future emissions from post-glacial subarctic

100 lakes are based on current measurements of temperature responsiveness ${ }^{1}$,

101 which are dominated by ebullitive flux data from shallow lake edges because

102 those locations currently experience a longer period of sufficient warmth for

103 seasonal emissions than lake middles ( $\sim 3$ months relative to $\sim 1$ month $)^{2}$. If, as

104 suggested here by our spatially resolved emissions data, temperature

105 responsiveness is substantively higher in the deeper sediments, then, as deeper

106 regions warm and remain heated for longer before cooling off in the fall, future

107 lake emissions would be greater than currently predicted. Thus, accurate $\mathrm{CH}_{4}$

108 emission predictions rely on understanding the spatial heterogeneity and

109 underlying causes of this temperature responsiveness.

110 Ebullition is controlled by $\mathrm{CH}_{4}$ production (which is in turn driven by redox,

111 substrates, temperature, and microbiota), consumption (driven by redox and

112 microbiota $)^{17-19}$, and the physics of bubble formation and escape (determined by

113 sediment texture and overlying hydrostatic pressure, which is largely controlled

114 by atmospheric conditions) $)^{2,15}$. Therefore, the edge-to-middle difference in 
115 temperature responsiveness of $\mathrm{CH}_{4}$ ebullition could be partly due to differences

116 in physicochemical characteristics (e.g., sediment texture, pressure, and redox),

117 substrates (e.g., organic carbon), and/or microbiota (abundance, composition,

118 and/or activity) ${ }^{20}$. Although differences in sediment texture were observed

119 between the lake edge and middle in Mellersta Harrsjön, these differences were

120 not consistent between lakes (Figure S2, Supplementary Table 3). Our previous

121 work has shown higher and more variable ebullition rates during periods of

122 dropping atmospheric pressure, but there were no differences in edge versus

123 middle locations ${ }^{9}$. In terms of redox, we expect concentrations of terminal

124 electron acceptors to be low, as the likely source would be runoff ${ }^{21}$, and total

125 sulfur and nitrogen did not correlate with ebullition rates by lake or location ${ }^{15}$. In

126 terms of measured substrates, carbon:nitrogen $(\mathrm{C}: \mathrm{N})$ ratios and bulk ${ }^{13} \mathrm{C}_{\mathrm{TOC}}$

127 (indicative of vegetation composition) did not vary from edges to middles. Total

128 organic carbon (TOC) varied by lake, with similar concentrations observed

129 between lake edge and middle in Mellersta and appreciably higher TOC in

130 middle sediments in Inre Harrsjön. Carbon quality, as assessed by visual

131 comparisons of organic matter composition, revealed coarse, less decomposed

132 detritus gyttja (organic-rich, peat-derived mud) in the edge sediments of both

133 lakes, while middle sediments were characterized by fine-grained, generally

134 more decomposed detritus gyttja ${ }^{15}$. Thus, higher temperature responsiveness

135 occurred where there was lower potential substrate quality, suggesting that

136 substrate differences do not readily explain differences in $\mathrm{CH}_{4}$ emission 
137 responses to temperature in edge versus middle lake locations, although more

138 detailed substrate analyses could further evaluate this in future.

139 Next, we sought to characterize differences in microbiota that could

140 contribute to the observed temperature response differences in $\mathrm{CH}_{4}$ emissions.

141 We used a 16S rRNA gene amplicon sequencing approach to characterize

142 microbial community composition from the edge and middle cores from each lake

143 (Figure 2A-B, Supplementary Table 4). Although microbial community

144 composition differed most significantly by depth within the sediment (Figure S3,

145 Supplementary Table 5), as is typical for aquatic sediments ${ }^{22}$, significant

146 differences between lake edges and middles (Figure 2C, PERMANOVA $p=$

$1470.001)$ suggest that microbiota could contribute to the observed temperature

148 sensitivity in $\mathrm{CH}_{4}$ emissions. Indeed, methanogens (defined here as populations

149 from known methanogenic clades $^{23}$, Supplementary Table 4) were significantly

150 more abundant in lake middles than edges (Figure 2D, ANOVA $p=0.0001$ ),

151 while total microbial abundances correlated most strongly with depth and did not

152 exhibit edge vs. middle differences (Figure S4, Supplementary Table 6). Aerobic

153 methanotrophs, which are posited to have minimal impact on ebullitive loss due

154 to rapid bubble movement through sediment ${ }^{11}$, were confined to the surface

155 sediment layers as expected (Supplementary Table 7) and did not differ

156 significantly in composition or relative abundance between edges and middles

157 (ANOVA $p=0.76$ ). Anaerobic methanotroph abundances differed significantly

158 between lake edges and middles (ANOVA $p=0.014$, Supplementary Tables 7-8)

159 and were approximately one order of magnitude higher in edge sediments. 
160 Although this could suggest that increased anaerobic methane oxidation in the

161 edge sediments could contribute to the observed differences in temperature

162 sensitivity, these anaerobic methanotrophs comprised only $0.1 \%$ of the

163 community on average (up to $0.6 \%$, Supplementary Tables 4 and 7 ), and

164 ebullition is expected to largely bypass methane oxidation.

165 To test the relevance of these community differences to their observable

$166 \mathrm{CH}_{4}$ production potential, we performed 48 ex situ anaerobic incubations of edge

167 and middle sediments collected in 2012 (linked directly to our microbial and

168 biogeochemical data) and 2013 (from the same four core locations)

169 (Supplementary Table 9). These incubations at 5 and $22^{\circ} \mathrm{C}$ confirmed that the

170 lake-middle sediments had higher $\mathrm{CH}_{4}$ production potentials than lake-edge

171 sediments at both temperatures (Figure 3), paralleling their higher methanogen

172 abundances and indicating that the lake-middle methanogens can remain

173 metabolically active at higher temperatures, despite never yet experiencing them

174 in situ.

175 In order to relate microbiota from discrete depths to in situ $\mathrm{CH}_{4}$ ebullition,

176 we partitioned ebullition to its likely source depths. We applied isotope and mass

177 balance calculations to infer ebullitive loss ("fugitive $\mathrm{CH}_{4}$ ") at each depth, based

178 on stable carbon isotope values and porewater concentrations of $\mathrm{CH}_{4}$ and

179 dissolved inorganic carbon (DIC) (Supplementary Table 3). From this inferred

180 ebullitive loss, total production at each depth interval was calculated and

181 correlated with microbiota from the same depth. Mantel tests revealed a 
182 significant correlation between microbial community composition and fugitive $\mathrm{CH}_{4}$

$183(p=0.016)$ (Supplementary Table 5).

184 To more specifically investigate links between $\mathrm{CH}_{4}$-associated microbial

185 functional guilds and $\mathrm{CH}_{4}$ chemistry, we identified multiple known $\mathrm{CH}_{4}$-cycling

186 clades in the 16S rRNA gene amplicon data and applied targeted metagenomic

187 sequencing to a subset of samples to examine diagnostic genes for $\mathrm{CH}_{4}$ cycling

188 (and to assemble genomes for metabolic pathway reconstructions, discussed

189 further below). From the metagenomes, we recovered 5,470 examples

190 (sequencing reads) of 28 phylogenetically diverse functional genes indicative of

$191 \mathrm{CH}_{4}$ production (mcrA) and consumption (pmoA) potential (Figure S5,

192 Supplementary Table 10). We used partial least squares regressions (PLSR) and

193 multiple linear regression (MLR) analyses to predict porewater $\mathrm{CH}_{4}$

194 concentrations from methanogen and methanotroph relative abundances, as

195 measured via 16S rRNA gene amplicon sequencing data. When using either

196 PLSR or MLR to predict porewater $\mathrm{CH}_{4}$ concentrations, a better prediction was

197 achieved when both depth-resolved abiotic variables (i.e., depth, TOC, DIC,

$198{ }^{13} \mathrm{C}_{\text {TOC }}, \mathrm{S}$, and TOC:TS, see methods) and the relative abundances of predicted

$199 \mathrm{CH}_{4}$-cycling organisms were included (PLSR: $r^{2}=0.640, p=0.00001, \mathrm{MLR}$ :

200 adjusted $\left.r^{2}=0.752, p=0.0003\right)$, relative to including the abiotic variables alone

201 (PLSR: $r^{2}=0.390, p=0.002$, MLR: adjusted $r^{2}=0.532, p=0.0004$ ) (Figure

202 4A,B, Supplementary Table 11). These results suggest that direct measurements

203 of microbial abundances could contribute to more accurate predictions of future

$204 \mathrm{CH}_{4}$ emissions, consistent with previous statistical models that have linked 
205 specific microbiota to $\mathrm{C}$ - and/or $\mathrm{CH}_{4}$-cycling dynamics in marine ecosystems and 206 thawing permafrost peatlands ${ }^{24-28}$.

207 By expanding our PLSR analyses to consider the full microbial community,

208 in addition to known $\mathrm{CH}_{4}$-cyclers, our ability to predict $\mathrm{CH}_{4}$ concentrations

209 improved further. This analysis considered the following groupings of 16S rRNA

210 gene abundances as explanatory variables for the prediction of porewater $\mathrm{CH}_{4}$

211 concentrations: 1 ) each operational taxonomic unit (OTU) at $>1 \%$ relative

212 abundance in any sample (Supplementary Table 4), 2) summed lineage

213 abundances of all bacteria and archaea (mostly at the phylum or class levels,

214 see Figure S3 for groupings), and 3) summed abundances of the most highly

215 resolved lineage representative in the amplicon data for each metagenome-

216 assembled genome (MAG, a population genome computationally reconstructed

217 from shotgun metagenomic community DNA sequencing data, Supplementary

218 Table 12). In two cases, a MAG was linked directly to a specific OTU in the

219 amplicon data through a co-binned 16S rRNA gene sequence in the MAG, such

220 that the MAG relative abundance could be inferred from the amplicon data. In all

221 other cases, the summed abundances of amplicon OTUs in the same lineage as

222 the MAG were used as proxies for MAG abundances.

223 Four of the top five microbial groups most predictive of porewater $\mathrm{CH}_{4}$

224 concentrations in the PLSR analyses were lineages for which we were able to

225 reconstruct a MAG (Figure 4C, Supplementary Tables 13-14), thus organization

226 into MAGs helped to unravel the specific metabolic processes most predictive of

227 carbon chemistry. In total, five MAGs were reconstructed with > $85 \%$ 
228 completeness and $<6 \%$ contamination (Supplementary Discussion). The best

229 overall predictor of porewater $\mathrm{CH}_{4}$ concentrations was the Syntrophaceae class

230 of Deltaproteobacteria, which was considered in the PLSR analysis as the

231 summed abundance of all OTUs in this clade. Syntrophaceae are known to be

232 syntrophic (obligately mutualistic) with methanogens and produce the hydrogen

233 needed for methanogenesis ${ }^{29}$. Consistent with hydrogen production, the

234 Syntrophaceae MAG revealed 15 hydrogenase-associated genes, along with the

235 capacity to ferment diverse carbon compounds (particularly carbon-sulfur

236 compounds), with the added potential capacity for respiration (see

237 Supplementary Discussion). Though the Syntrophaceae were overall most

238 predictive of porewater $\mathrm{CH}_{4}$ concentrations, the most significantly predicitive

239 single OTU was a member of the candidate phylum Aminicenantes, which we

240 also recovered as a MAG. While this lineage has been previously predicted to be

241 fermentative, saccharolytic, and/or aerobic ${ }^{30-32}$, our lake sediment genome

242 revealed metabolic potential for several C1 metabolic processes, including

243 methylotrophy through the assimilation of methylamines, methane-thiols, and/or

244 dimethylsulfide, similar to previous recoveries of complete Wood-Ljungdahl

245 pathways for C1 metabolism via carbonyl and methyl pathways in this lineage ${ }^{33}$.

246 The predicted capacity for methylotrophy could explain the strong correlation

247 between Aminicenantes relative abundance and porewater $\mathrm{CH}_{4}$ concentrations.

248 The relative abundances of two other lineages with MAGs, the

249 Thermoplasmata (a group of Archaea) and Phycisphaerae (a class of

250 Planctomycetes bacteria), were also strongly predictive of both porewater $\mathrm{CH}_{4}$ 
251 concentrations in the PLSR analysis and of calculated fugitive $\mathrm{CH}_{4}$ in linear

252 regressions (Supplementary Tables 14-15). Phylogenetic analyses showed that

253 the Thermoplasmata MAG was derived from a divergent member of the

254 Thermoplasmatales order, and it encodes the capacity for $\mathrm{CO}_{2}$ production from

255 formate, along with peptide and amino acid degradation (as previously

256 indicated $^{34}$ ) and complex carbon degradation. Our recovered Phycisphaerae

257 population genome appears to have the capacity to metabolize a wide variety of

258 complex carbon compounds, potentially via fermentation, consistent with

259 previous predictions for the Planctomycetes phylum ${ }^{35}$. While direct ties to $\mathrm{CH}_{4}$

260 are not obvious in these two genomes, we speculate that their contributions to

261 overall carbon cycling may be driving these strong correlations with $\mathrm{CH}_{4}$

262 concentrations and emissions.

263 Interestingly, the only lineage represented by a MAG that was not a

264 significant predictor of porewater $\mathrm{CH}_{4}$ concentrations in the PLSR analysis was a

265 member of the archaeal Methanomassiliicoccales, a lineage previously

266 presumed to consist exclusively of obligate $\mathrm{H}_{2}$-dependent methylotrophic

267 methanogens ${ }^{36,37}$. While we cannot make a definitive claim based on a single

268 MAG, we hypothesize that our lake sediment Methanomassiliicoccales

269 population does not have the capacity for methanogenesis, as we did not recover

270 any genes from the methanogenesis pathway in this $95 \%$ complete genome. The

271 genome does encode a complete pathway for propionate fermentation and

272 partial pathways that may be indicative of the potential to ferment benzoate,

273 butyrate, and succinate. 
274 In conclusion, we found significant differences in the slope of the

275 temperature vs. $\mathrm{CH}_{4}$ flux relationship between sub-arctic lake edges and

276 middles, suggesting that radiative forcing (temperature) and a concomitant

277 increase in microbial metabolic rates are not the only primary controls on $\mathrm{CH}_{4}$

278 emissions. Significant differences in microbial community composition between

279 lake edges and middles, including significantly higher methanogen abundances

280 in lake middles, and significantly higher $\mathrm{CH}_{4}$ emissions from lake middle

281 sediments when incubated at the same temperatures as lake edges suggest that

282 sediment microbial community composition contributes to spatial differences in

283 the response of $\mathrm{CH}_{4}$ emissions to increasing temperature. In addition, the

284 abundances of $\mathrm{CH}_{4}$-cycling organisms and their reconstructed population

285 genomes (MAGs) were significantly better predictors of sediment $\mathrm{CH}_{4}$

286 concentrations than abiotic variables alone. Syntrophic lineages, which can

287 generate the hydrogen required for hydrogenotrophic methanogenesis, and

288 lineages capable of $\mathrm{C}$ degradation to $\mathrm{CO}_{2}$ (also potentially 'upstream' of

289 methanogenesis) were also predictive of sediment $\mathrm{CH}_{4}$ concentrations. Together,

290 these results suggest that when lake middles reach the temperatures of lake

291 edges, they may emit even more $\mathrm{CH}_{4}$ than the lake edges currently do, such that

292 our projected future $\mathrm{CH}_{4}$ emissions may be underestimating contributions from

293 subarctic lakes, and that knowledge of microbial community composition and

294 metabolism could improve these predictions. Future investigations that consider

295 the combined effects of microbiota, carbon quality, and temperature on lake $\mathrm{CH}_{4}$ 
296 emissions will help to provide a more comprehensive understanding of

297 spatiotemporal controls on global $\mathrm{CH}_{4}$ emissions.

298

\section{Methods}

300 Field site and sample collection

301 Stordalen Mire is a subarctic peatland complex located $10 \mathrm{~km}$ east of

302 Abisko in northern Sweden $\left(68^{\circ} 21^{\prime} \mathrm{N}, 19^{\circ} 02^{\prime} \mathrm{E}\right)$. Lakes Mellersta Harrsjön and

303 Inre Harrsjön are 1.1 and 2.3 ha in area, reaching maximum depths of 7 and $5 \mathrm{~m}$,

304 respectively ${ }^{38}$. These lakes are post-glacially formed. Mellersta Harrsjön receives

305 water from a small stream while Inre Harrsjön is fed through groundwater and

306 runoff from the surrounding mire. Ebullitive and diffusion-limited $\mathrm{CH}_{4}$ emissions

307 from these lakes have been documented, using floating funnels and chambers

308 distributed across the lakes and sampled frequently ${ }^{2,9,12}$. Ebullition varies

309 spatially with higher emissions from shallow zones and in the presence of

310 plants $^{9,15}$.

311 We collected quadruplicate sediment cores (four cores from two locations

312 in each of two lakes: Mellersta Harrsjön edge $\left(68^{\circ} 357832{ }^{\prime} \mathrm{N}, 1^{\circ} 042046^{\prime} \mathrm{E}\right)$ and

313 middle $\left(68^{\circ} 358291^{\prime} \mathrm{N}, 1^{\circ} 042132\right.$ 'E) and Inre Harrsjön edge (68³57880’N,

$\left.3141^{\circ} 048525^{\prime} \mathrm{E}\right)$ and middle (68 $\left.\left.358418^{\prime} \mathrm{N}, 1^{\circ} 045650^{\prime} \mathrm{E}\right)\right)$ on July 10 and 18, 2012

315 at the Stordalen Mire nature reserve, a research site near Abisko, northern

316 Sweden (Supplementary Table 1). Samples were taken from cores (as described

317 below) along a depth gradient (ranging from $4-40 \mathrm{~cm}$ ) for geochemical

318 measurements and microbial DNA sequencing data. 


\section{Geochemical data collection and analysis}

320 For each set of four cores, we sampled the first core for sediment C, N,

321 and $\mathrm{S}$ (weight percent), percent total organic carbon, and bulk sediment ${ }^{13} \mathrm{C}_{\mathrm{TOC}}$

322 and ${ }^{15} \mathrm{~N}_{\text {TOc. }}$ Samples of $1 \mathrm{~cm}^{3}$ were taken in $6 \mathrm{~cm}$ increments from the top of the

323 core to the bottom. The samples were then dried, ground, and split into an

324 untreated sample for total carbon (C) and an acidified TOC sample. Details

325 regarding sample preparation for measurement on a Perkin Elmer 2400 Series II

326 CHNS/O Elemental Analyzer at the University of New Hampshire (UNH) were

327 described previously ${ }^{15}$. Repeatability error was established by analyzing replicate

328 samples and calculating the standard deviation. Duplicate samples were run

329 approximately every 10 samples. Potential outliers were also run in duplicate.

330 Isotopic analysis was performed by combusting dried sediment samples in a

331 Costech ECS 4010 elemental analyzer coupled to a Thermo Trace GC Ultra

332 isotope ratio mass spectrometer (IRMS), based on calibration with acetanilide,

333 Atlantic cod, black spruce needles, sorghum flour, corn gluten, NIST 1515 apple

334 leaves and tuna muscle standards (UNH Stable Isotope Lab). In 2013 we also

335 collected sediment cores in the same locations in these lakes. We report

336 sediment textural analyses from these cores as \% sand, \% silt, and \% clay

337 (Supplementary Table 3). Those samples were dried and run through a laser

338 particle size analyzer (Malvern Mastersizer 2000).

339 The second replicate core was used for quantifying total $\mathrm{CH}_{4}$ in the core

340 sediment reported in $\mu \mathrm{M}$. After coring, we pulled $2 \mathrm{~cm}^{3}$ sediment plugs using cut

341 plastic syringes through pre-drilled holes cut at $4 \mathrm{~cm}$ increments along the core 
342 liner. The sediment plugs were transferred to $30 \mathrm{ml}$ serum vials containing $5 \mathrm{ml}$

343 of $2 \mathrm{M} \mathrm{NaOH}$, capped quickly and shaken ${ }^{39,40}$. After sitting overnight then heating

344 for 1 hour at $60^{\circ} \mathrm{C}$, the headspace of the vials was analyzed for $\mathrm{CH}_{4}$ using a

345 Shimadzu GC-2014 gas chromatograph with a flame ionizing detector ${ }^{9}$. The $\mathrm{CH}_{4}$

346 measured represents the total, that is, nearly all of the $\mathrm{CH}_{4}$ dissolved in the water

347 from the sediment plug and any bubbles that may have been trapped in the

348 sediment. The remaining sediment samples in the vials were weighed and dried

349 to constant weight to determine the mass of water in the samples to be used for

350 calculating the $\mathrm{CH}_{4}$ concentration in $\mu \mathrm{M}$.

351 The third replicate core was used for measurement of DIC. Rhizon

352 samplers were inserted every $2 \mathrm{~cm}$ through pre-drilled holes in the core and a

353 vacuum was pulled with a $30 \mathrm{ml}$ polypropylene syringe. The first $\sim 1 \mathrm{ml}$ of

354 sediment water was discarded because of contamination with DI water. After 10

$355 \mathrm{ml}$ of sediment pore water was collected, it was injected to a $30 \mathrm{ml}$ evacuated

356 serum vial with $1 \mathrm{ml} 30 \% \mathrm{H}_{4} \mathrm{PO}_{4}$ solution. This caused forms of inorganic $\mathrm{C}$ in the

357 water to form $\mathrm{CO}_{2}$. A headspace sample was then extracted and run on an

358 infrared gas analyzer (IRGA) to determine the $\mathrm{CO}_{2}$ concentration.

359 Methods for measuring ebullition and water temperature have been

360 described previously ${ }^{9}$. In brief, measurements of $\mathrm{CH}_{4}$ bubble flux during the ice-

361 free season (June to September) have been ongoing at these lakes since 2009.

362 A total of 40 bubble traps, distributed in a depth-stratified sampling scheme were

363 sampled frequently (every 1-3 days). For this study, averages of $\mathrm{CH}_{4}$ bubble flux

364 were calculated for each lake by binning data from edge and middle areas 
365 separately in $1^{\circ} \mathrm{C}$ intervals (total of $4-22^{\circ} \mathrm{C}$ ) of corresponding surface sediment

366 temperature. For this we used flux and temperature data collected from 2009-

367 2014. Water and surface sediment temperatures were measured in profiles

368 continuously using intercalibrated Onset HOBO v22 loggers, as previously

369 described $^{9}$ (data are available here: https://bolin.su.se/data/). The binned flux

370 data were used to construct Arrhenius equations in order to investigate

371 differences in temperature response on the ebullition from edge and middle

372 areas.

373 Porewater isotopic composition was determined in samples from cores

374 collected in the same locations in 2014. Methods were described previously ${ }^{24}$.

375 Briefly, sample vials that were collected for $\mathrm{CH}_{4}$ and dissolved inorganic carbon

376 (DIC) were acidified with $0.5 \mathrm{ml}$ of $21 \% \mathrm{H}_{3} \mathrm{PO}_{4}$ and brought to atmospheric

377 pressure with helium. The sample headspace was analyzed for $\mathrm{d} 13 \mathrm{C}$ of $\mathrm{CH}_{4}$ and

$378 \mathrm{CO}_{2}$ on a continuous-flow Hewlett-Packard 5890 gas chromatograph (Agilent

379 Technologies) at $40^{\circ} \mathrm{C}$ coupled to a FinniganMAT Delta $\mathrm{S}$ isotope ratio mass

380 spectrometer via a Conflo IV interface system (Thermo Scientific).

382 DNA extraction and 16S rRNA gene sequencing

383 A fourth replicate core was collected for DNA extraction. After coring, we

384 pulled $2 \mathrm{~cm}^{3}$ sediment plugs using cut plastic syringes through pre-drilled holes

385 cut at $4 \mathrm{~cm}$ increments along the core liner. Samples were immediately put in

386 Eppendorf tubes and placed in a cooler until returned to the research station

387 where they were stored at $-80^{\circ} \mathrm{C}$ until extraction. 
For DNA extraction from each core depth range, $0.25 \mathrm{~g}$ of sediment was

389 collected under sterile conditions and added to a MoBio PowerSoil DNA Isolation

390 Kit (MoBio, Inc., Carlsbad, CA, USA). DNA was extracted according to the

391 manufacturer's instructions. PCR amplification and sequencing were performed

392 at the Environmental Sample Preparation and Sequencing Facility (ESPSF) at

393 Argonne National Laboratory, in accordance with previously described

394 protocols $^{41-43}$. Briefly, 515F and barcoded $806 \mathrm{R}$ primers with Illumina flowcell

395 adapter sequences were used to amplify the V4 region of bacterial and archaeal

396 16S rRNA genes ${ }^{44}$. Each $25 \mu$ I PCR reaction contained $12 \mu$ l of PCR water

397 (MoBio, Inc., Carlsbad, CA, USA), $10 \mu$ l of 1x 5 PRIME Hot Master Mix (5 PRIME

398 Inc., Bethesda, MD, USA), $1 \mu$ l each of F and R primers ( $5 \mu \mathrm{M}$ concentration,

$399200 \mathrm{pM}$ final), and $1 \mu \mathrm{l}$ of template DNA. PCR cycling conditions were as follows:

$40094^{\circ} \mathrm{C}$ for $3 \mathrm{~min}, 35$ cycles of $\left[94^{\circ} \mathrm{C}\right.$ for $45 \mathrm{~s}, 50^{\circ} \mathrm{C}$ for $60 \mathrm{~s}$, and $72{ }^{\circ} \mathrm{C}$ for $90 \mathrm{~s}$ ],

$40172{ }^{\circ} \mathrm{C}$ for $10 \mathrm{~min}$. A PicoGreen assay (Life Technologies, Grand Island, NY, USA)

402 was used to measure amplicon concentrations. Equimolar concentrations for

403 each barcoded sample were combined and then cleaned with the UltraClean

404 PCR Clean-Up Kit (MoBio Inc., Carlsbad, CA, USA) and then quantified using the

405 Qubit (Invitrogen, Carlsbad, CA, USA). The pool was then diluted to $2 \mathrm{nM}$,

406 denatured, and then diluted to a final concentration of $4 \mathrm{pM}$ with a $10 \%$ PhiX

407 spike for sequencing on the Illumina MiSeq platform.

408 Quantitative PCR (qPCR)

409 A quantitative polymerase chain reaction (qPCR) was performed to

410 measure microbial abundances in units of 16S rRNA gene copies per g wet 
411 sediment ${ }^{43,45}$. Each reaction used $5 \mu$ l of $2 X$ SYBR Green PCR Master Mix

412 (Applied Biosystems, Carlsbad, CA, USA), $4 \mu$ l of template DNA, and $1 \mu$ l of

413 primer mix. The $16 \mathrm{~S}$ rRNA gene $1406 \mathrm{~F} / 1525 \mathrm{R}$ primer set $(0.4 \mu \mathrm{M}, \mathrm{F}$ -

414 GYACWCACCGCCCGT and R - AAGGAGGTGWTCCARCC) was designed to

415 amplify bacterial and archaeal $16 \mathrm{~S}$ rRNA genes. The rpsL primer pair $(0.2 \mu \mathrm{M}, \mathrm{F}$

416 - GTAAAGTATGCCGTGTTCGT and R - AGCCTGCTTACGGTCTTTA) was

417 used for inhibition control samples to amplify Escherichia coli DH10B only. Three

418 dilutions $(1 / 100,1 / 500$, and $1 / 1000)$, as well as an inhibition control $(1 / 100$

419 dilution of E. coli DH10B genomic DNA spiked into a 1/100 dilution of the sample),

420 were run in triplicate for each sample and standard. For the standards, E. coli

421 DH10B genomic DNA dilutions of $10^{-2}, 10^{-3}, 10^{-4}, 10^{-5}$ and $10^{-6}$ of the $20 \mathrm{ng} / \mu \mathrm{l}$

422 stock solution were used. The qPCRs were run on the ViiA7 Real-Time PCR

423 System (Applied Biosystems, Carlsbad, CA, USA), with cycling conditions as

424 follows: 10 min at $95^{\circ} \mathrm{C}, 40$ cycles of $\left[15 \mathrm{~s}\right.$ at $95^{\circ} \mathrm{C}$, then $20 \mathrm{~s}$ at $55^{\circ} \mathrm{C}$, then 30

$425 \mathrm{~s}$ at $72^{\circ} \mathrm{C}$ ]. A melt curve was produced by running a cycle of 2 min at $95^{\circ} \mathrm{C}$ and

426 a final cycle of $15 \mathrm{~s}$ at $60^{\circ} \mathrm{C}$. The cycle threshold (Ct) values were recorded and

427 analyzed using ViiA7 v1.2 software, and 16S rRNA gene copy numbers were

428 calculated for each sample, accounting for the genome size $(4,686,137 \mathrm{bp})$ and

429 16S rRNA gene copy number (7) of the standard.

430 Incubations for $\mathrm{CH}_{4}$ production rates

431 Anaerobic incubations of lake sediment samples were performed to

432 assess rates of production of $\mathrm{CH}_{4}$. Four replicate sediment samples (4 ml) from

433 three depths in $2012(0-5,10,20 \mathrm{~cm})$ were collected in the field and immediately 
434 sealed in a $120 \mathrm{ml}$ serum vial. The headspace was flushed for 5 minutes with

435 UHP $\mathrm{N}_{2}$ to establish an anaerobic headspace. The vials were stored in coolers,

436 taken to the research station, and then stored as follows: 2 vials were incubated

437 at $5^{\circ} \mathrm{C}$ and 2 vials were held at room temperature $\left(22^{\circ} \mathrm{C}\right)$ for each depth. Five $\mathrm{ml}$

438 of headspace was sampled daily for five days and analyzed on a Flame

439 Ionization Gas Chromatograph (GC) to determine $\mathrm{CH}_{4}$ fluxes. Fluxes were

440 normalized by sediment mass after incubations when vials were dried and

441 weighed to determine sediment dry weight. We also report data from incubations

442 in 2013 that were run the same way with samples collected at depths consistent

443 with changes in core sediment transitions: Inre Harrsjön edge: $2.5,27.5,47.5 \mathrm{~cm}$;

444 Inre Harrsjön middle: 4.5, 35, 60 cm; Mellersta Harrsjön edge: 7.5, 22.5, 37.5 cm;

445 and Mellersta Harrsjön middle: $2.5,27.5,47.5 \mathrm{~cm}$.

446 Calculations of depth-resolved fugitive $\mathrm{CH}_{4}$

447 Depth-resolved fugitive $\mathrm{CH}_{4}\left(\mathrm{CH}_{4}\right.$ released from the sediments) was

448 calculated from concentration and stable carbon isotopic composition of $\mathrm{CH}_{4}$ and

449 DIC in sediment porewater ${ }^{46}$. The approach leverages that fact that 1) microbial

450 fermentation and respiration, which generate $\mathrm{CO}_{2}$, do not fractionate carbon,

451 while methanogenesis, which generates $\mathrm{CH}_{4}$ and $\mathrm{CO}_{2}(1: 1)$, does fractionate

452 carbon, and 2) that DIC largely remains dissolved in water while dissolved $\mathrm{CH}_{4}$

453 escapes porewater by ebullition. In this framework, the measured isotopic

454 composition of $\mathrm{CH}_{4}$ in porewater was used to calculate the fraction factor

455 associated with methanogenesis, assuming the starting isotopic composition of

456 the substrate matched that measured for organic carbon in the sediment. This 
457 fractionation factor, along with the measured isotopic composition of DIC in

458 porewater, was used to determine the relative amount of DIC that came from

459 methanogeneis versus non-fractionating pathways (e.g., fermentation). Because

460 any $\mathrm{CO}_{2}$ produced was assumed to stay dissolved in porewater, the relative

461 amount of DIC generated from methanogenesis could be multiplied by the

462 measured concentration of DIC to determine the concentration of $\mathrm{CO}_{2}$ and $\mathrm{CH}_{4}$

463 generated through methanogenesis. This generated $\mathrm{CH}_{4}$ concentration was

464 larger than the actual measured concentration of $\mathrm{CH}_{4}$ in porewater, and the

465 difference between the two was assigned as 'fugitive' methane. Calculations

466 assumed that the system was at steady state.

467 16S rRNA gene sequence processing and OTU table generation for microbial

468 analyses

469 Sequences were processed as previously described ${ }^{43}$. Briefly, after

470 demultiplexing by sample, each pair of forward and reverse 16 S rRNA gene

471 reads was merged. Sequences were then quality-filtered, and singletons were

472 removed with QIIME ${ }^{47}$ and UPARSE ${ }^{48}$. Dereplicated sequences were then

473 clustered at $97 \%$ nucleotide identity using UCLUST v $7^{49}$ to generate a database

474 containing one sequence for each operational taxonomic unit (OTU). Sequencing

475 reads from the full dataset were then clustered to the database to generate an

476 OTU table. Each OTU was assigned taxonomy via the Ribosomal Database

477 Project taxonomic classifier ${ }^{50}$, and all OTUs assigned as mitochondria or

478 chloroplasts were removed. The resulting OTU table was rarefied to 3,000 $16 \mathrm{~S}$

479 rRNA gene sequences per sample. Following this OTU table curation, 36 
480 samples across 21 core-depth combinations were retained, of which 30 were

481 replicates (i.e., 15 pairs). For each pair of replicates, each OTU count was

482 averaged (for 14 of 15 pairs, replicates were indistinguishable, Figure S6), and

483 the averages were used for all downstream analyses. For the six samples

484 without successful replicates, OTU counts from a single sample were used.

485 Metagenomic sequencing, genome reconstruction and annotation, and methane-

486 cycling functional gene characterization

487 Based on preliminary 16S rRNA gene amplicon sequencing data from 8

488 samples (IHM4, IHM36, IHE4, IHE28, MHM4, MHM34, MHE4, and MHE16),

489 three samples with the most distinct microbial communities (IHM4, IHE28, and

490 MHE16) were selected for metagenomic sequencing to maximize recovery of

491 diverse microbial populations. DNA (from the same extractions described above

492 for 16S rRNA gene sequencing) was sent to the Australian Centre for

493 Ecogenomics for metagenomic library construction and sequencing on the

494 Illumina NextSeq platform, as previously described ${ }^{25,26}$. Metagenomic assembly,

495 genome binning to recover microbial metagenome-assembled genomes (MAGs),

496 and annotation (to predict gene functions and reconstruct metabolic pathways)

497 were performed as previously described ${ }^{51}$. Briefly, each metagenome was

498 separately assembled using the CLC de novo assembler v4.4.1 (CLCBio,

499 Denmark), reads were mapped to contigs using BWA v0.7.12-r1039 ${ }^{52}$, and the

500 mean coverage of contigs was obtained using the 'coverage' command of

501 CheckM v1.0.6 ${ }^{53}$. Genomes were binned using MetaBAT v0.26.3 ${ }^{54}$ with all five

502 preset parameters (verysensitive, sensitive, specific, veryspecific, superspecific), 
503 and genome completeness and contamination were estimated using $\mathrm{CheckM}^{53}$.

504 To investigate predicted metabolic functions of interest in the metagenomic data,

505 metagenomic reads with sequence similarity to genes diagnostic of specific

506 metabolic functions (e.g., methane monooxygenase, pmoA, and methyl-

507 coenzyme $\mathrm{M}$ reductase, $\mathrm{mcr}$, indicative of aerobic methane oxidation and

508 methanogenesis, respectively) were identified using GraftM ${ }^{55}$.

509 Sequencing data availability

510 Data are currently available here: https://isogenie-db.asc.ohio-

511 state.edu/datasources\#lake_data. Upon publication, sequencing data from this

512 study will be available at NCBI, with accession numbers provided here.

\section{Statistical analyses}

$514 \quad$ Unless otherwise indicated, statistical analyses were performed using

515 PRIMER v7 $7^{56,57}$. The rarefied OTU table was square-root transformed, and Bray-

516 Curtis similarity matrices were generated for sample comparisons and used to

517 make a Principal Coordinates Analysis (PCoA) plot. We used permutational

518 ANOVA (PERMANOVA) to test for significant differences in microbial community

519 composition between categorical groups of samples (e.g., between the two lakes

520 and between the edges and middles of the lakes), and we used Mantel tests with

521 Spearman's rank correlations to compare microbial community composition

522 (Bray-Curtis similarity matrices) to continuous variables (Euclidean distance

523 matrices), including sediment depth and biogeochemical data. ANOVA and linear

524 regression analyses (Supplementary Tables 8 and 15) were performed with

525 StatPlus v6.1.7.0. 
526 We performed partial least squares regressions (PLSR) in the R

527 programming language via the package PLS (function PLSR) ${ }^{58-60}$ to predict

528 measured sediment $\mathrm{CH}_{4}$ concentrations from biotic and abiotic variables, similar

529 to our previously described PLSR analyses ${ }^{25}$. Briefly, PLSR models a causal

530 relationship between explanatory variable(s) (in this case, abundances of abiotic

531 measurements and/or microorganisms) and the response variable being

532 predicted (here, measured sediment $\mathrm{CH}_{4}$ concentrations). Abiotic variables

533 included all depth-resolved abiotic measurements that were not directly related to

$534 \mathrm{CH}_{4}$, as such measurements could be confounding variables in our analysis. The

535 included abiotic variables were: depth, TOC, ${ }^{13} \mathrm{C}_{\mathrm{TOC}}$, DIC, S, and TOC:TS. The

536 PLSR analysis yielded Pearson's product moment correlations between

537 measured environmental and/or geochemical variables, the abundances of

538 microbial lineages, and the abundances of specific microbial populations,

539 allowing for a quantification of the added value of microbial abundances in

540 predicting sediment $\mathrm{CH}_{4}$ concentrations, relative to predictions from abiotic

541 factors alone. Variance in projection (VIP) scores for each explanatory variable

542 indicate the extent to which that variable was predictive of the response variable

543 (i.e., sediment $\mathrm{CH}_{4}$ concentrations), with VIP scores $\geq 1$ considered to be highly

544 significant ${ }^{61}$.

545

546 Acknowledgements

547 We would like to acknowledge the following funding in support of this

548 project: the Northern Ecosystems Research for Undergraduates program 
549 (NERU; National Science Foundation REU site EAR-1063037, PI Varner), a U.S.

550 National Science Foundation MacroSystems Biology grant (NSF EF

$551 \quad \# 1241037$, PI Varner), U.S. Department of Energy grants (DE-SC0010580 and

552 DE-SC0016440, Co-lead PI Rich; DE-SC0010338 and DE-SC0019063, PI

553 Neumann), the Swedish Research Council (VR) with grants to P. Crill (2007-

5544547 and 2013-5562). Thanks to staff at the Polar Research Secretariat's Abisko

555 Research Station (ANS). Thanks to Kaitlyn Steele, Florencia Fahnestock, Kiley

556 Remiszewski, Carmody McCalley, and NERU participants Sophia Burke, Joel

557 DeStasio, Lance Erickson, and Madison Halloran for assistance in sample

558 collection and analysis, and Jacob Setera and Steve Phillips (UNH) for

559 assistance with the CHNS elemental analysis.

560

\section{References}

562

563

1 Wik, M., Varner, R. K., Anthony, K. W., MacIntyre, S. \& Bastviken, D.

564

565

566

567

568

569

570

571

572

573

574

575

576

577

578

579

580

581 Climate-sensitive northern lakes and ponds are critical components of methane release. Nature Geosci 9, 99-105, doi:10.1038/ngeo2578 (2016).

2 Wik, M. et al. Energy input is primary controller of methane bubbling in subarctic lakes. Geophysical Research Letters 41, 555-560, doi:10.1002/2013GL058510 (2014).

3 Holgerson, M. A. \& Raymond, P. A. Large contribution to inland water $\mathrm{CO} 2$ and $\mathrm{CH} 4$ emissions from very small ponds. Nature Geosci 9 , 222-

226, doi:10.1038/ngeo2654 (2016).

4 Tan, Z. \& Zhuang, Q. Arctic lakes are continuous methane sources to the atmosphere under warming conditions. Environmental Research Letters 10, 054016, doi:10.1088/1748-9326/10/5/054016 (2015).

5 Verpoorter, C., Kutser, T., Seekell, D. A. \& Tranvik, L. J. A global inventory of lakes based on high-resolution satellite imagery. Geophysical Research Letters 41, 6396-6402, doi:10.1002/2014GL060641 (2014).

6 Walter, K. M., Smith, L. C. \& Chapin, F. S. Methane bubbling from northern lakes: present and future contributions to the global methane budget. Philosophical Transactions of the Royal Society A: Mathematical, Physical, and Engineering Sciences 365, 1657-1676 (2007). 


\begin{tabular}{|c|c|c|}
\hline $\begin{array}{l}582 \\
583\end{array}$ & 7 & $\begin{array}{l}\text { van Huissteden, J. et al. Methane emissions from permafrost thaw lakes } \\
\text { limited by lake drainage. Nature Clim. Change 1, 119-123 (2011). }\end{array}$ \\
\hline 84 & 8 & Schuur, E. A. G. et al. Vulnerability of Permafrost Carbon to Climate \\
\hline 35 & & Change: Implications for the Global Carbon Cycle. BioScience 58, 701- \\
\hline 36 & & 714, doi:10.1641/B580807 (2008). \\
\hline 37 & 9 & Wik, M., Crill, P. M., Varner, R. K. \& Bastviken, D. Multiyear \\
\hline 38 & & measurements of ebullitive methane flux from three subarctic lakes. \\
\hline 39 & & Journal of Geophysical Research: Biogeosciences 118, 1307-1321, \\
\hline 90 & & doi:10.1002/jgrg.20103 (2013). \\
\hline 91 & 10 & Bastviken, D., Tranvik, L. J., Downing, J. A., Crill, P. M. \& Enrich-Prast, A. \\
\hline 2 & & Freshwater Methane Emissions Offset the Continental Carbon Sink. \\
\hline 93 & & Science 331, 50, doi:10.1126/science.1196808 (2011). \\
\hline 94 & 11 & $\begin{array}{l}\text { Chanton, J. P. The effect of gas transport on the isotope signature of } \\
\text { methane in wetlands. Organic Geochemistry } 36,753-768,(2005) \text {. }\end{array}$ \\
\hline 96 & 12 & Jansen, J. et al. Climate-Sensitive Controls on Large Spring Emissions of \\
\hline 97 & & CH4 and CO2 From Northern Lakes. Journal of Geophysical Research: \\
\hline 98 & & Biogeosciences 124, 2379-2399, doi:10.1029/2019JG005094 (2019). \\
\hline 99 & 13 & Lundin, E. J. et al. Is the subarctic landscape still a carbon sink? Evidence \\
\hline & & from a detailed catchment balance. Geophysical Research Letters 43, \\
\hline & & 1988-1995, doi:10.1002/2015GL066970 (2016). \\
\hline 2 & 14 & Thornton, B. F., Wik, M. \& Crill, P. M. Climate-forced changes in available \\
\hline & & energy and methane bubbling from subarctic lakes. Geophysical \\
\hline & & Research Letters 42, 1936-1942, doi:10.1002/2015GL063189 (2015). \\
\hline 05 & 15 & Wik, M. et al. Sediment Characteristics and Methane Ebullition in Three \\
\hline & & Subarctic Lakes. Journal of Geophysical Research: Biogeosciences 123, \\
\hline 07 & & 2399-2411, doi:10.1029/2017JG004298 (2018). \\
\hline 08 & 16 & Tranvik, L. J. et al. Lakes and reservoirs as regulators of carbon cycling \\
\hline 9 & & and climate. Limnol. Oceanogr. 54, 2298-2314, \\
\hline 10 & & doi:10.4319/lo.2009.54.6_part_2.2298 (2009). \\
\hline 611 & 17 & Alperin, M. J., Albert, D. B. \& Martens, C. S. Seasonal variations in \\
\hline 12 & & production and consumption rates of dissolved organic carbon in an \\
\hline $12+>>1$ & & organic-rich coastal sediment. Geochimica et Cosmochimica Acta 58, \\
\hline 14 & & $4909-4930(1994)$ \\
\hline 615 & 18 & Duc, N. T., Crill, P. \& Bastviken, D. Implications of temperature and \\
\hline 616 & & sediment characteristics on methane formation and oxidation in lake \\
\hline 617 & & sediments. Biogeochemistry 100, 185-196, doi:10.1007/s10533-010-9415- \\
\hline 618 & & $8(2010)$ \\
\hline 619 & 19 & Winkel, M. et al. First evidence for cold-adapted anaerobic oxidation of \\
\hline 620 & & methane in deep sediments of thermokarst lakes. Environmental \\
\hline 621 & & Research Communications 1, 021002 (2019). \\
\hline 622 & 20 & Ruuskanen, M. O., St. Pierre, K. A., St. Louis, V. L., Aris-Brosou, S. \& \\
\hline 623 & & Poulain, A. J. Physicochemical Drivers of Microbial Community Structure \\
\hline 624 & & in Sediments of Lake Hazen, Nunavut, Canada. Frontiers in Microbiology \\
\hline 625 & & 9, doi:10.3389/fmicb.2018.01138 (2018). \\
\hline 626 & 21 & Kokfelt, U. et al. Wetland development, permafro \\
\hline 627 & & mit recoras in \\
\hline
\end{tabular}


628

629

630

631

632

633

634

635

636

637

638

639

640

641

642

643

644

645

646

647

648

649

650

651

652

653

654

655

656

657

658

659

660

661

662

663

664

665

666

667

668

669

670

671

672

subarctic Sweden. Journal of Paleolimnology 44, 327-342,

doi:10.1007/s10933-010-9406-8 (2010).

22 Rissanen, A. J. et al. Vertical stratification of bacteria and archaea in sediments of a small boreal humic lake. FEMS Microbiology Letters 366, doi:10.1093/femsle/fnz044 (2019).

23 Evans, P. N. et al. An evolving view of methane metabolism in the Archaea. Nature Reviews Microbiology 17, 219-232, doi:10.1038/s41579018-0136-7 (2019).

24 McCalley, C. K. et al. Methane dynamics regulated by microbial community response to permafrost thaw. Nature 514, 478-481, (2014).

25 Emerson, J. B. et al. Host-linked soil viral ecology along a permafrost thaw gradient. Nature Microbiology 3, 870-880, doi:10.1038/s41564-018-0190-y (2018).

26 Woodcroft, B. J. et al. Genome-centric view of carbon processing in thawing permafrost. Nature, doi:10.1038/s41586-018-0338-1 (2018).

27 Johnston, E. R. et al. Responses of tundra soil microbial communities to half a decade of experimental warming at two critical depths. Proceedings of the National Academy of Sciences, 201901307, doi:10.1073/pnas.1901307116 (2019).

28 Zinke, L. A. et al. Microbial Organic Matter Degradation Potential in Baltic Sea Sediments Is Influenced by Depositional Conditions and In Situ Geochemistry. Applied and Environmental Microbiology 85, e02164-02118, doi:10.1128/AEM.02164-18 (2019).

29 Morris, B. E. L., Henneberger, R., Huber, H. \& Moissl-Eichinger, C. Microbial syntrophy: interaction for the common good. FEMS Microbiology Reviews 37, 384-406, doi:10.1111/1574-6976.12019 (2013).

30 Sharon, I. et al. Accurate, multi-kb reads resolve complex populations and detect rare microorganisms. Genome Research, doi:10.1101/gr.183012.114 (2015).

31 Kadnikov, V. V., Mardanov, A. V., Beletsky, A. V., Karnachuk, O. V. \& Ravin, N. V. Genome of the candidate phylum Aminicenantes bacterium from a deep subsurface thermal aquifer revealed its fermentative saccharolytic lifestyle. Extremophiles 23, 189-200, doi:10.1007/s00792018-01073-5 (2019).

32 Robbins, S. J., Evans, P. N., Parks, D. H., Golding, S. D. \& Tyson, G. W. Genome-Centric Analysis of Microbial Populations Enriched by Hydraulic Fracture Fluid Additives in a Coal Bed Methane Production Well. Frontiers in Microbiology 7, doi:10.3389/fmicb.2016.00731 (2016).

33 Gies, E. A., Konwar, K. M., Beatty, J. T. \& Hallam, S. J. Illuminating Microbial Dark Matter in Meromictic Sakinaw Lake. Applied and Environmental Microbiology 80, 6807, doi:10.1128/AEM.01774-14 (2014).

34 Lloyd, K. G. et al. Predominant archaea in marine sediments degrade detrital proteins. Nature 496, 215-218 (2013).

35 Spring, S., Bunk, B., Spröer, C., Rohde, M. \& Klenk, H.-P. Genome biology of a novel lineage of planctomycetes widespread in anoxic aquatic 
673

674

675

676

677

678

679

680

681

682

683

684

685

686

687

688

689

690

691

692

693

694

695

696

697

698

699

700

701

702

703

704

705

706

707

708

709

710

711

712

713

714

715

716

717

718

environments. Environmental Microbiology 0, doi:10.1111/1462-

2920.14253 (2018).

36 Borrel, G. et al. Comparative genomics highlights the unique biology of Methanomassiliicoccales, a Thermoplasmatales-related seventh order of methanogenic archaea that encodes pyrrolysine. BMC Genomics 15, 679, doi:10.1186/1471-2164-15-679 (2014).

37 Vanwonterghem, I. et al. Methylotrophic methanogenesis discovered in the archaeal phylum Verstraetearchaeota. Nature Microbiology 1, 16170 (2016).

38 Wik, M., Crill, P. M., Bastviken, D., Danielsson, A. \& Norbäck, E. Bubbles trapped in arctic lake ice: Potential implications for methane emissions. Journal of Geophysical Research: Biogeosciences 116, doi:10.1029/2011JG001761 (2011).

39 Magen, C. et al. A simple headspace equilibration method for measuring dissolved methane. Limnology and Oceanography: Methods 12, 637-650, doi:10.4319/lom.2014.12.637 (2014).

40 Pimmel, A. \& Claypool, G. Introduction to shipboard organic chemistry on the JOIDES Resolution. (2001).

41 Bates, S. T. et al. Examining the global distribution of dominant archaeal populations in soil. ISME J 5, 908-917 (2011).

42 Lauber, C. L., Ramirez, K. S., Aanderud, Z., Lennon, J. \& Fierer, N.

Temporal variability in soil microbial communities across land-use types. ISME J 7, 1641-1650 (2013).

43 Emerson, J. B. et al. Impacts of Flood Damage on Airborne Bacteria and Fungi in Homes after the 2013 Colorado Front Range Flood.

Environmental Science \& Technology 49, 2675-2684, doi:10.1021/es503845j (2015).

44 Caporaso, J. G. et al. Global patterns of 16S rRNA diversity at a depth of millions of sequences per sample. Proceedings of the National Academy of Sciences 108, 4516-4522, doi:10.1073/pnas.1000080107 (2010).

45 Emerson, J. B. et al. High temporal variability in airborne bacterial diversity and abundance inside single-family residences. Indoor Air 27, 576-586, doi:10.1111/ina.12347 (2017).

46 Corbett, J. E. et al. Partitioning pathways of $\mathrm{CO} 2$ production in peatlands with stable carbon isotopes. Biogeochemistry 114, 327-340, doi:10.1007/s10533-012-9813-1 (2013).

47 Caporaso, J. G. et al. QIIME allows analysis of high-throughput community sequencing data. Nat Meth 7, 335-336 (2010).

48 Edgar, R. C. UPARSE: highly accurate OTU sequences from microbial amplicon reads. Nat Meth 10, 996-998 (2013).

49 Edgar, R. C. Search and clustering orders of magnitude faster than BLAST. Bioinformatics, doi:10.1093/bioinformatics/btq461 (2010).

50 Wang, Q., Garrity, G. M., Tiedje, J. M. \& Cole, J. R. Naive Bayesian Classifier for Rapid Assignment of rRNA Sequences into the New Bacterial Taxonomy. Applied and Environmental Microbiology 73, 52615267, doi:10.1128/aem.00062-07 (2007). 
$71951 \quad$ Parks, D. H. et al. Recovery of nearly 8,000 metagenome-assembled

720

721

722

723

724

725

726

727

728

729

730

731

732

733

734

735

736

737

738

739

740

741

742

743

744

745

746

747

748

749

750 genomes substantially expands the tree of life. Nature Microbiology 2, 1533-1542, doi:10.1038/s41564-017-0012-7 (2017).

$52 \mathrm{Li}, \mathrm{H}$. \& Durbin, R. Fast and accurate short read alignment with BurrowsWheeler transform. Bioinformatics 25, 1754-1760, doi:10.1093/bioinformatics/btp324 (2009).

53 Parks, D. H., Imelfort, M., Skennerton, C. T., Hugenholtz, P. \& Tyson, G. W. CheckM: assessing the quality of microbial genomes recovered from isolates, single cells, and metagenomes. Genome Research, doi:10.1101/gr.186072.114 (2015).

54 Kang, D. D., Froula, J., Egan, R. \& Wang, Z. MetaBAT, an efficient tool for accurately reconstructing single genomes from complex microbial communities. PeerJ 3, e1165, doi:10.7717/peerj.1165 (2015).

55 Boyd, J. A., Woodcroft, B. J. \& Tyson, G. W. GraftM: a tool for scalable, phylogenetically informed classification of genes within metagenomes. Nucleic Acids Research 46, e59-e59, doi:10.1093/nar/gky174 (2018).

56 Clarke, K. R. Non-parametric multivariate analyses of changes in community structure. Australian Journal of Ecology 18, 117-143, doi:10.1111/j.1442-9993.1993.tb00438.x (1993).

57 Clarke, K. R. \& Gorley, R. N. PRIMER v6: User Manual/Tutorial. (Plymouth, 2006).

58 Lê Cao, K.-A., Rossouw, D., Robert-Granié, C. \& Besse, P. in Statistical Applications in Genetics and Molecular Biology Vol. 7 (2008).

59 Shen, H. \& Huang, J. Z. Sparse principal component analysis via regularized low rank matrix approximation. J. Multivar. Anal. 99, 10151034, doi:10.1016/j.jmva.2007.06.007 (2008).

60 Guidi, L. et al. Plankton networks driving carbon export in the oligotrophic ocean. Nature 532, 465-470 (2016).

61 Chong, I.-G. \& Jun, C.-H. Performance of some variable selection methods when multicollinearity is present. Chemometrics and Intelligent Laboratory Systems 78, 103-112 (2005). 
Figure 1
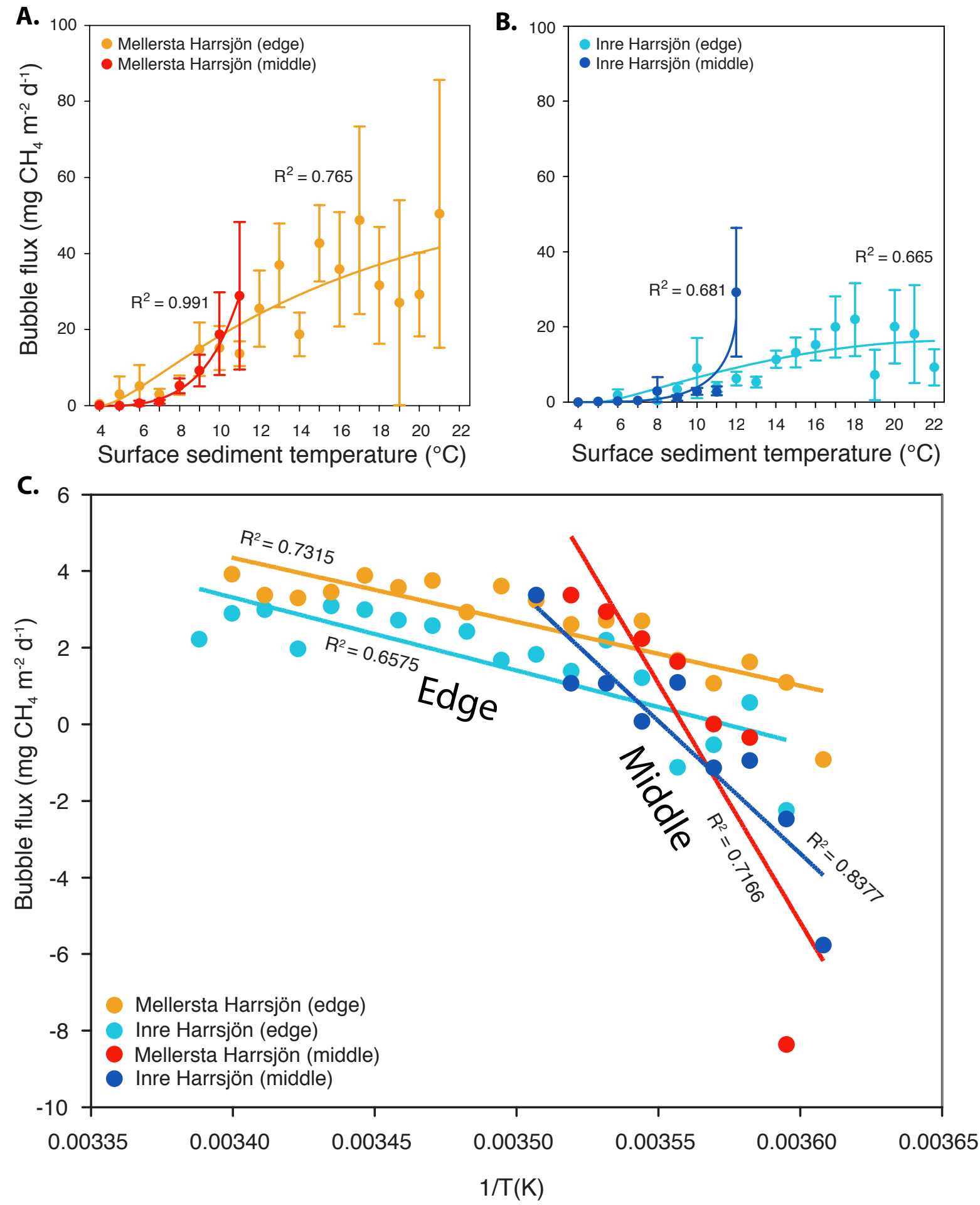

Figure 1. Temperature responsiveness of ebullitive methane flux from two postglacial lakes. Ebullitive $\mathrm{CH}_{4}$ flux as a function of surface sediment temperature (data were binned in $1^{\circ} \mathrm{C}$ intervals; see methods) for the edge versus middle regions of:

A. Lake Mellersta Harrsjön (MH) and B. Lake Inre Harrsjön $(\mathrm{IH})$, from June - September 2009 - 2014; $\mathrm{MH}$ edge $-n=1,609$, MH middle $-n=810$, IH edge $-n=2,347$, IH middle $n=549$. Error bars are $95 \%$ confidence intervals, fit lines are 2 nd degree polynomials. C. Arrhenius plots of the data in $\mathrm{A} \& \mathrm{~B}$; In (bubble $\mathrm{CH}_{4}$ flux) versus the inverse surface sediment temperature in K. Data are color-coded by lake and by edge and middle areas. 
Figure 2

A.

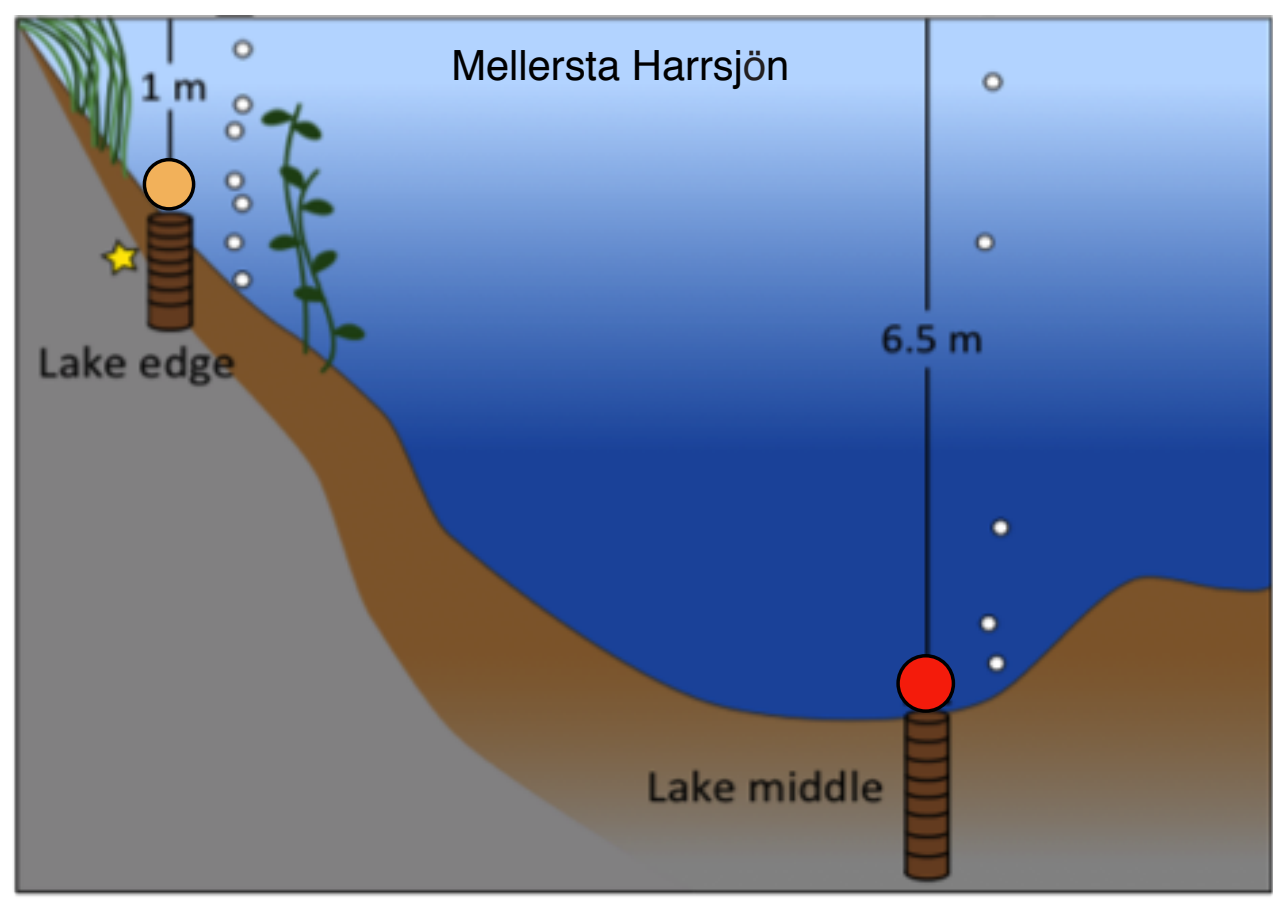

B.

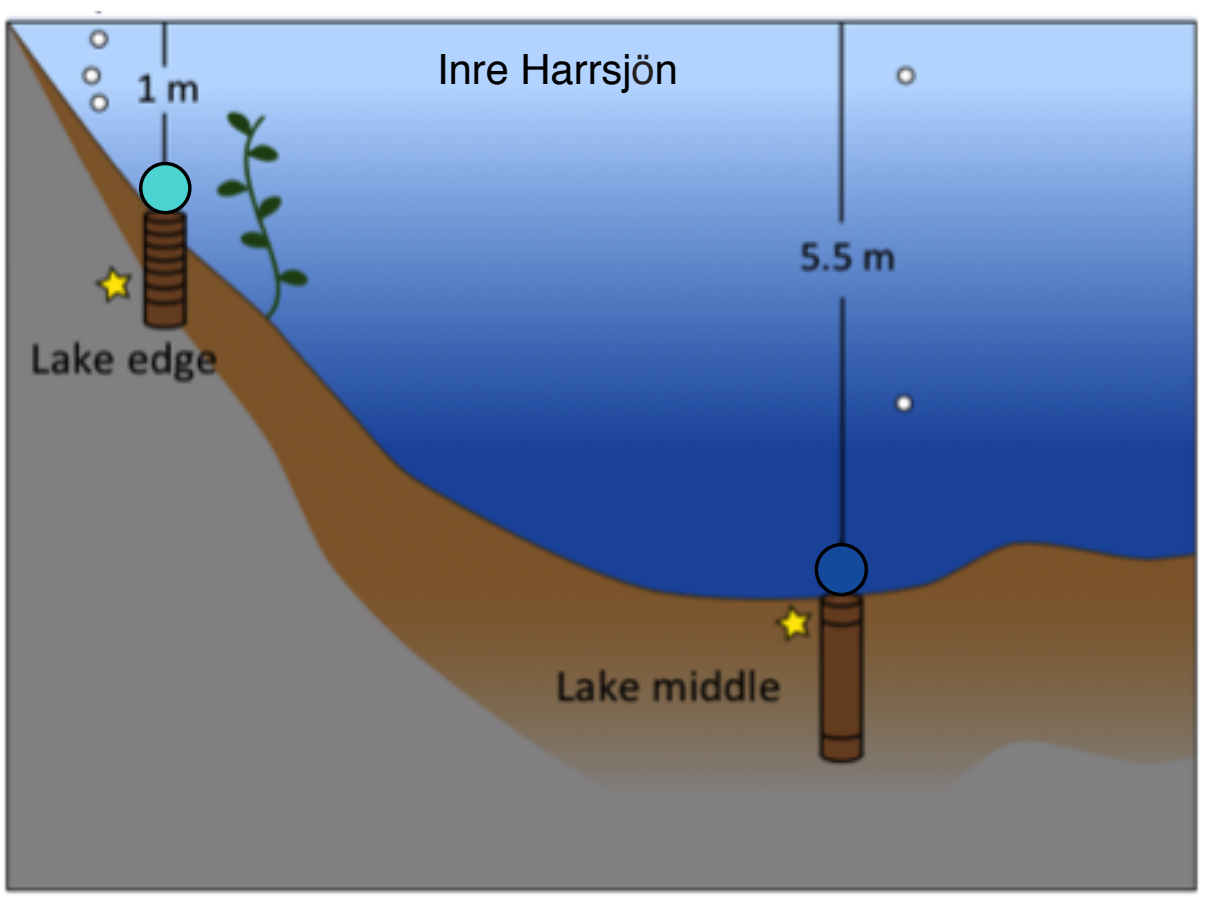

c.

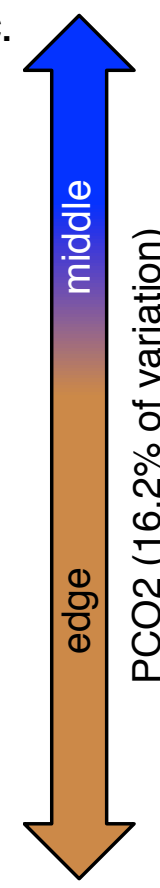

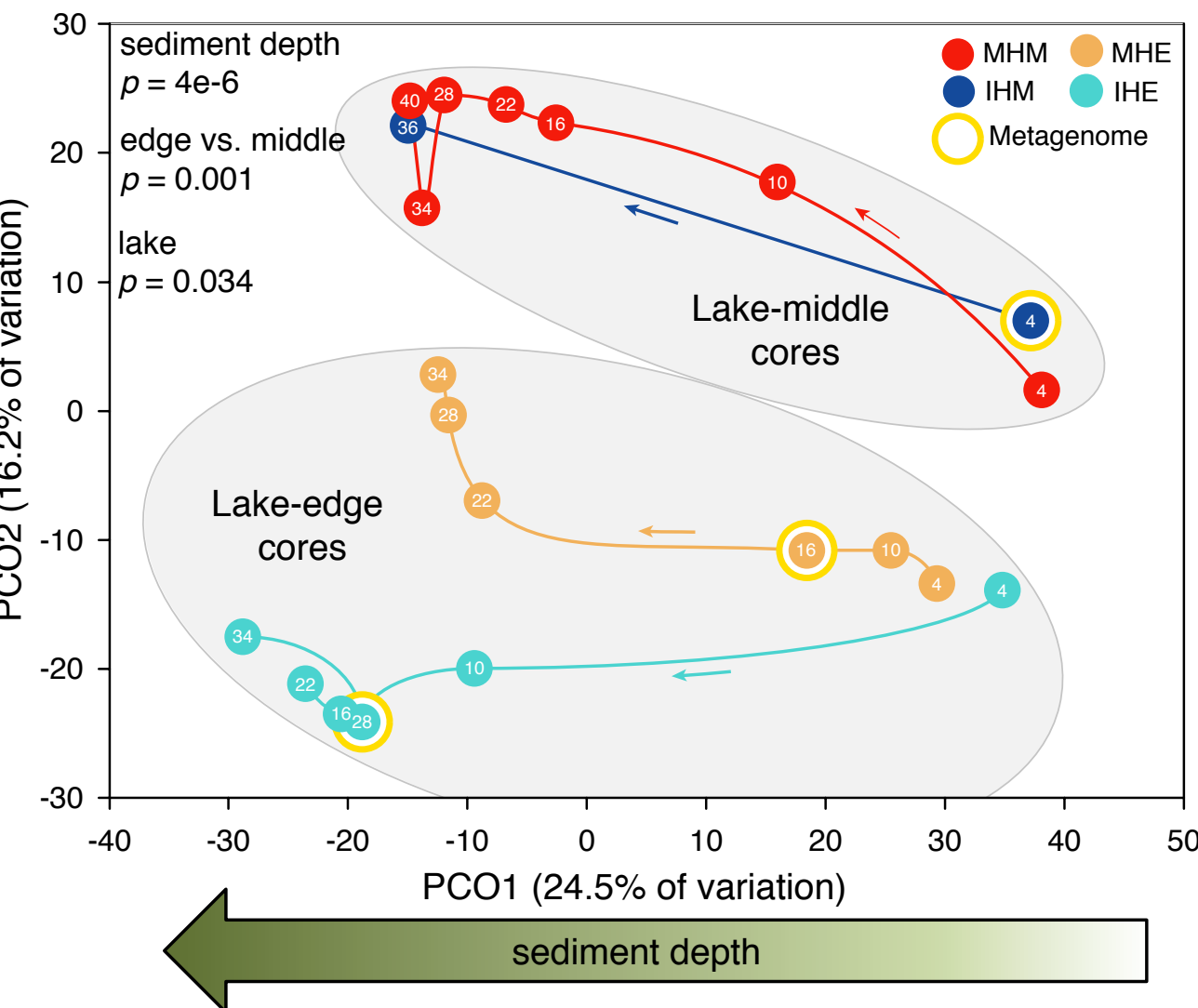

D.

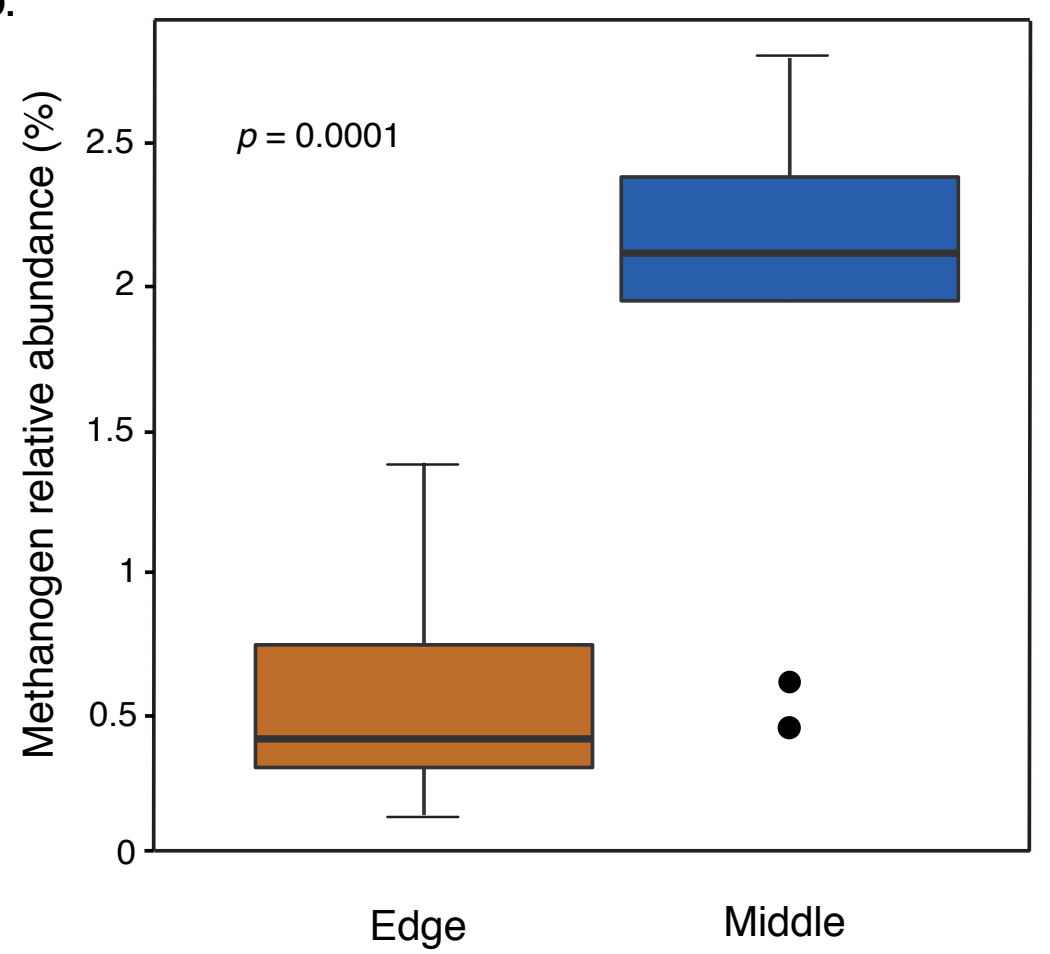

Figure 2. Lake sediment bacteria and archaea in two post-glacial lakes. A, B. Schematic overview of lakes and cores collected for DNA sequencing analyses, with core subsections indicated by horizontal lines. Cores in each lake are referred to as "Lake edge" or "Lake middle", with overlying water depth as indicated, and the four colored circles are used to distinguish each core and/or lake location throughout the figures. Yellow stars indicate cores and depths targeted for shotgun metagenomics. C. Principal coordinates analysis (PCoA) of microbial community composition across samples (each core subsection, $n=21$ ), based on $16 \mathrm{~S}$ rRNA gene amplicon abundances of microbial operational taxonomic units (OTUs); circles represent samples, and samples in closer proximity have more similar microbial community composition. Thin arrows along colored lines indicate increasing depth within each core. P-values from PERMANOVA indicate how significantly microbial community composition differed according to the indicated categorical variable (significant if $p<0.05$ ). D. Percent relative abundance of OTUs identified as methanogens in $16 \mathrm{~S}$ rRNA gene amplicon data in lake edges compared to lake middles (P-value from Student's T-test, significant if $p<0.05$ ). 
Figure 3

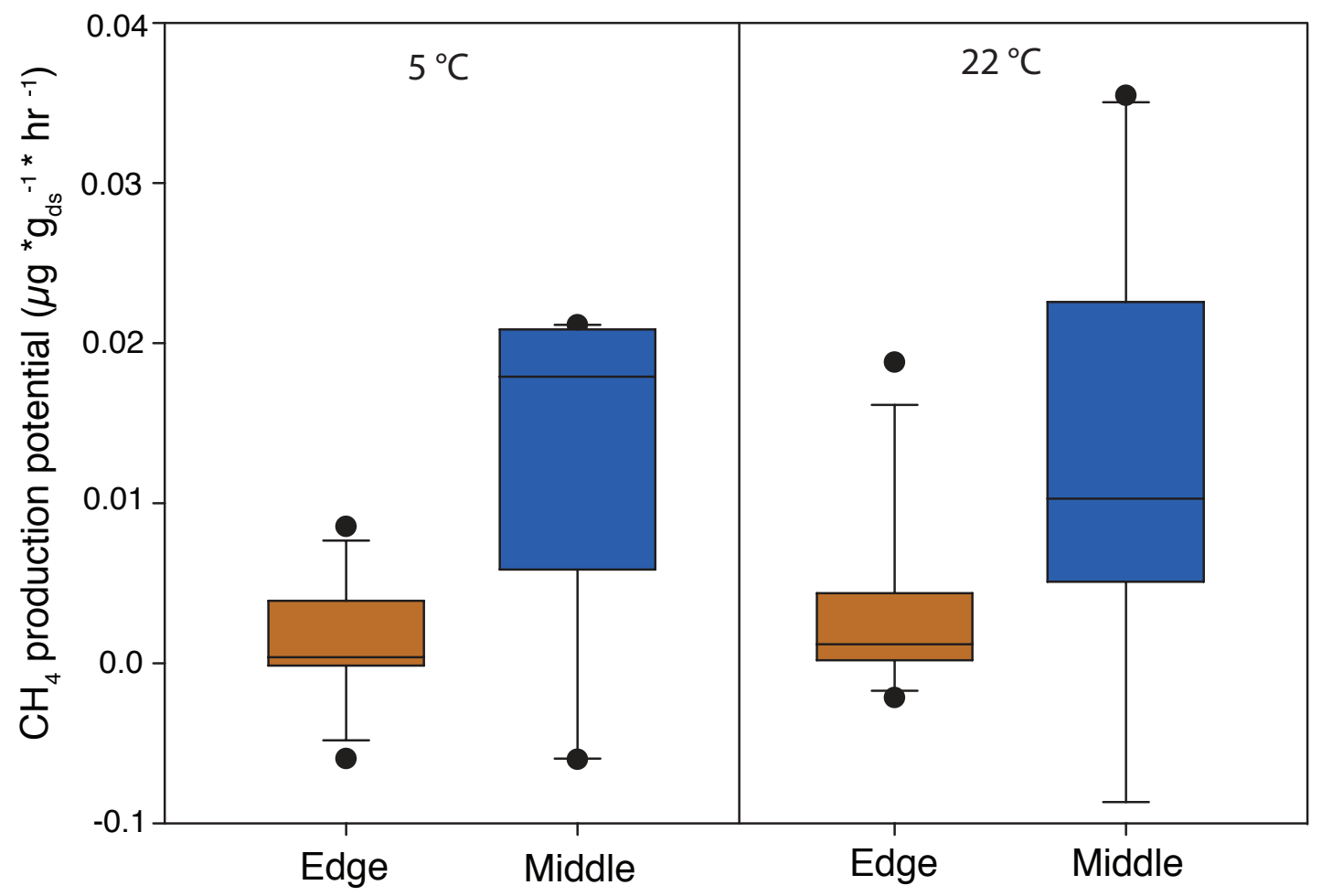

Figure 3. Methane production from anaerobic laboratory incubations of lake sediments. Sediments were collected from edges and middles of lakes Inre Harrsjön and Mellersta Harrsjön in 2012 and 2013 (see methods) and incubated at A. $5^{\circ} \mathrm{C}(n=12)$ and $\mathbf{B} .22^{\circ} \mathrm{C}(n=12)$. Headspace $\mathrm{CH}_{4}$ concentrations were measured daily for 5 days, and average daily $\mathrm{CH}_{4}$ fluxes were calculated for each sample. Lines in boxes depict the median, boxes indicate 75th percentile, whiskers 95th percentile, and points are outliers. $d s=$ dry sediment. 
A.

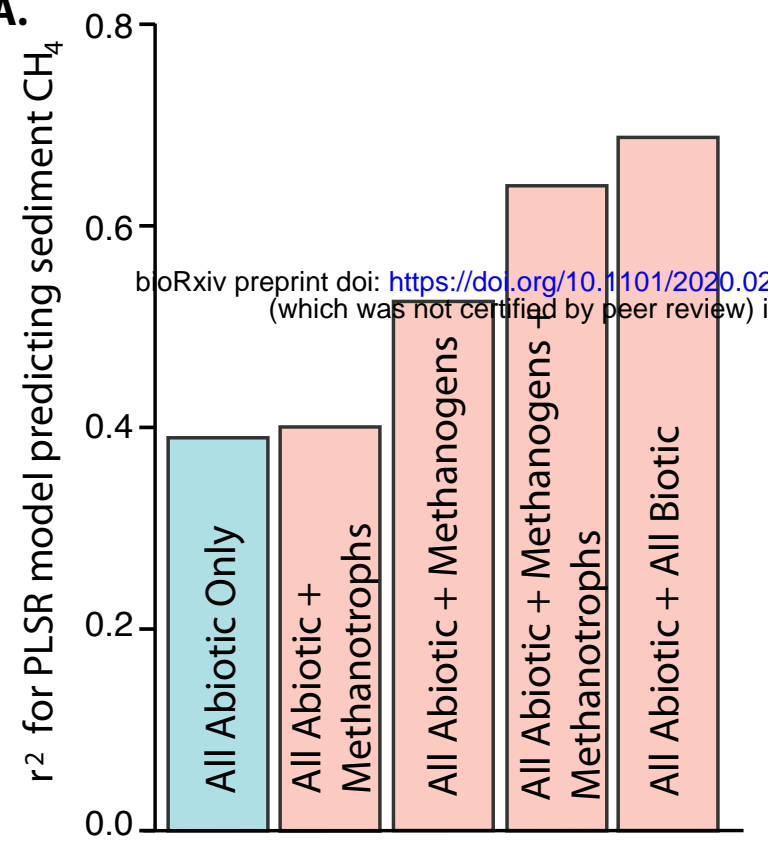

C.

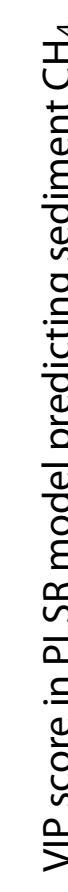

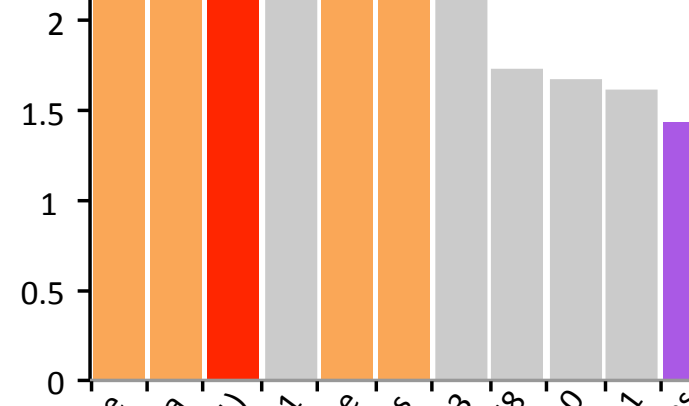

B.

Explanatory Variables (Predictors):

All Abiotic + Methanogens + Methanotrophs

$$
r^{2}=0.640
$$

r 0.640

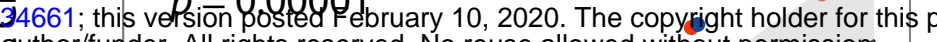

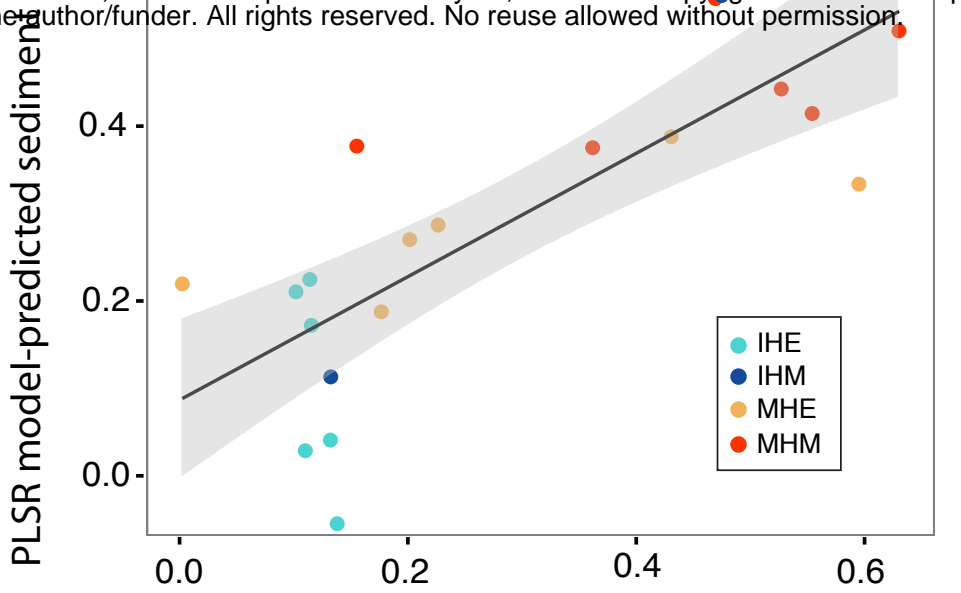

Measured sediment $\mathrm{CH}_{4}(\mathrm{mM})$
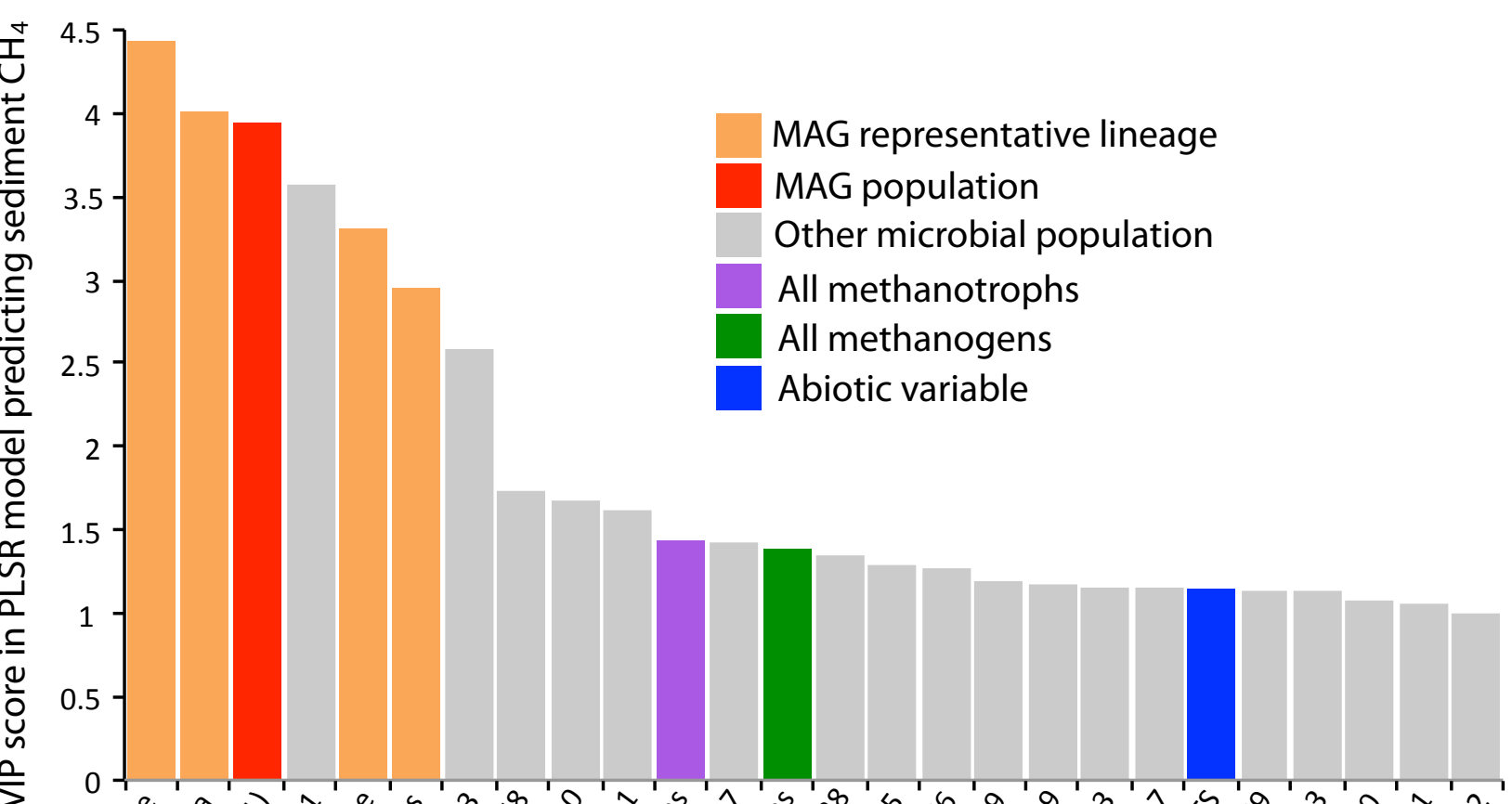

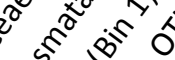
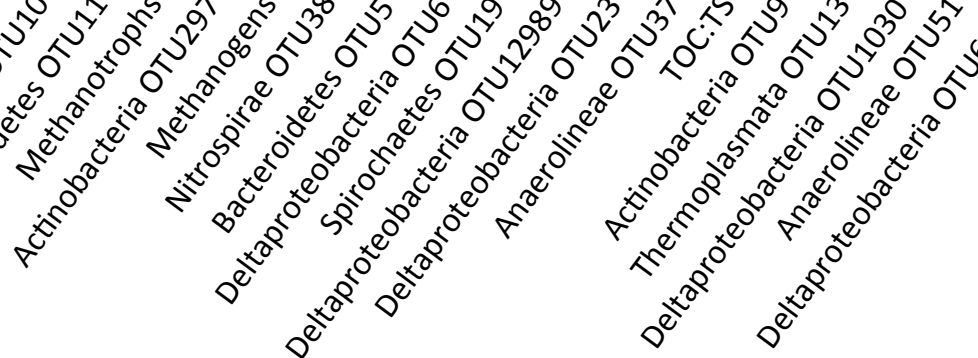

Explanatory Variable (Predictor)

Figure 4. Partial Least Squares Regression (PLSR) statistical modeling to predict sediment $\mathbf{C H}_{\mathbf{4}}$ concentrations. PLSR analyses tested the ability of different suites of explanatory variables to predict measured sediment $\mathrm{CH}_{4}$ concentrations in the four cores from 2012 across depths $(n=21)$; in all models, all measured abiotic variables (except those related to $\mathrm{CH}_{4}$ concentrations, see methods) were included as explanatory variables, and biotic variables were added as indicated. Biotic variables included relative abundances of specific OTUs and/or summed OTU abundances grouped by taxonomy or predicted metabolism (as indicated), from 16S rRNA gene amplicon data. A. Correlation coefficients $\left(\mathrm{r}^{2}\right)$ for PLSR models predicting sediment $\mathrm{CH}_{4}$ using different combinations of explanatory variables. B. Linear regression of measured and model-predicted sediment $\mathrm{CH}_{4}$, considering all abiotic variables and methanogen and methanotroph abundances as explanatory variables; each point is a sample, colored by core. C. For the model with the highest $r^{2}$ (rightmost in panel A), VIP scores are plotted to indicate the relative contribution of each explanatory variable; a VIP score $>1$ is considered significant, and higher VIP scores indicate a more significant contribution to the model; all VIP scores $>1$ are shown ( $n=26$ out of $n=153$ total, Supplementary Table 14). 